\title{
The effect of winding angles on crushing behavior of filament wound hollow kenaf yarn fibre reinforced unsaturated polyester composites
}

\begin{abstract}
This study investigates the effect of filament winding angles on the crushing behavior of hollow kenaf fibre yarn reinforced unsaturated polyester composites produced by the filament winding technique. The two winding angles studied were $\pm 45^{\circ}$ and $\pm 90^{\circ}$. The experimental work was conducted using a filament winding machine modified from an existing lathe machine. Load-displacement curves were obtained from the study. From the loaddisplacement response of the composite specimens, the crashworthiness parameters were obtained. This investigation showed that the initial failure was dominated by the interfacial and shear failure, while the delamination and eventually fibre fracture dominated the failure mechanism after the initial failure. It is also found that the static crushing behaviour of the structural hollow composite is very sensitive to the change in different winding angles between $\pm 45^{\circ}$ and $\pm 90^{\circ}$. The novel findings of this work include reinforcement of a shaft with aluminum greatly affects the energy absorption of the structural hollow composites and filament wound composites have good energy absorption capability as well as these materials are suitable to be used in highly loaded components in automotive and structural applications. It can be concluded that energy is dependent on the effect of the angles between the $90^{\circ}$ and $45^{\circ}$ hollow composites. The angle of $45^{\circ}$ of wound hollow composites tends to absorb more energy in crushing due to their longest distance in the post-crushing zone.
\end{abstract}

Keyword: Filament winding; Kenaf; Crashworthiness bahaviour; Unsaturated polyester; Winding angles 